\title{
AIR POLLUTION AND EMERGENCY ADMISSIONS FOR CARDIORESPIRATORY DISEASES IN LISBON (PORTUGAL)
}

Célia A. Alves*

Centro de Estudos do Ambiente e do Mar, Departamento de Ambiente e Ordenamento, Universidade de Aveiro, 3810-193 Aveiro, Portugal Manuel G. Scotto

Departamento de Matemática, Universidade de Aveiro, 3810-193 Aveiro, Portugal

Maria do Carmo Freitas

Instituto Tecnológico e Nuclear, E.N. 10, 2686-953 Sacavém, Portugal

Recebido em 6/3/09; aceito em 30/7/09; publicado na web em 11/1/10

\begin{abstract}
AIR POLLUTION AND EMERGENCY ADMISSIONS FOR CARDIORESPIRATORY DISEASES IN LISBON (PORTUGAL). Daily records of hospital admissions due to cardiorespiratory diseases and levels of $\mathrm{PM}_{10}, \mathrm{SO}_{2}, \mathrm{CO}, \mathrm{NO}, \mathrm{NO}_{2}$, and $\mathrm{O}_{3}$ were collected from 1999-2004 to evaluate the relationship between air pollution and morbidity in Lisbon. Generalised additive Poisson regression models were adopted, controlling for temperature, humidity, and both short and long-term seasonality. Significant positive associations, lagged by 1 or 2 days, were found between markers of traffic-related pollution $\left(\mathrm{CO}\right.$ and $\left.\mathrm{NO}_{2}\right)$ and cardiocirculatory diseases in all age groups. Increased childhood emergency admissions for respiratory illness were significantly correlated with the 1-day lagged $\mathrm{SO}_{2}$ levels coming from industrial activities.
\end{abstract}

Keywords: atmospheric pollutants; health effects; Poisson models.

\section{INTRODUCTION}

It is well known that bad air quality causes ill health and death. Breathing small amounts of air pollution over many years is also considered hazardous. The most susceptible to air pollution exposure are the elderly, and those with inflammatory disorders of the respiratory airways, such as asthma or severe bronchitis. ${ }^{1,2}$ Children are at greater risk because their lungs are still growing. On the other hand, they play more actively outside, breathing more outdoor polluted air than most adults.

Possible links between air pollution, particularly that caused by atmospheric particles and $\mathrm{SO}_{2}$, and the number of hospital admissions have been recently established in studies from North America, ${ }^{3-12}$ South America, ${ }^{13-16}$ Asia, ${ }^{17-22}$ Australia ${ }^{22}$ and Europe. ${ }^{23-35}$ However, there are still many aspects to elucidate the causal relationships between air pollution and physical condition, such as the separation of the short-term and long-term health effects of individual air pollutants and those of complex pollutant mixtures. Trends toward managing numerous pollutants to maximise aggregate health gains consign increasing value on knowing whether the effects of mixtures of pollutants are greater than the sum of the effects of individual pollutants (synergy). ${ }^{36}$ In general, the epidemiological models to estimate the health outcomes of air pollution give lower risks in Europe than in the United States, with the lowest effects being observed in Australia. ${ }^{37,38}$ This may suggest exposition to different pollution levels and diverse susceptibilities of the populations. On the other hand, these observations indicate that conclusions within a particular country may not be willingly assignable to other regions. ${ }^{37}$ Therefore, more research is needed to infer specific regional links between air pollution and adverse health effects. Considering the uncertainties about the health effects of air pollutants and given the fact that this kind of investigation is rather inexistent in Portugal, a study was performed using Poisson time series regression models for the complete study population, and for subgroups, admitted to hospital emergencies for cardiorespiratory illness in Lisbon during 1999-2004.

*e-mail: celia.alves@ua.pt

\section{EXPERIMENTAL}

\section{Studied area}

Lisbon is the biggest urban area in Portugal with a population density of 7,272 inhabitants per $\mathrm{km}^{2}$ and a total area of $84 \mathrm{~km}^{2}$. At the time of the study, $15.6 \%$ of the Lisbon population were children and adolescents under $14,67.9 \%$ were in the range 15-64 years old, and $16.5 \%$ were elderly people. Lisbon is set on seven terraced hills, north of the Tagus river estuary at $38^{\circ} 44^{\prime} \mathrm{N}, 9^{\circ} 8^{\prime} \mathrm{W}$ (Figure 1). Industries include textiles, chemicals, steel, oil and sugar refining, shipbuilding, soap and flour production. Traffic is the main source of atmospheric pollution in the city. In winter winds blow mostly from SW, W, and NE, but from March onwards, there is a great increase in the frequency of northerly winds (Figure 1S, supplementary material). Owing to its location on the Atlantic coast and the winds regime, high levels of pollutants are uncommon. Nevertheless, under adverse meteorological conditions, low dispersion conditions and thermic inversions, particularly in winter, high concentrations of air pollutants can be registered.

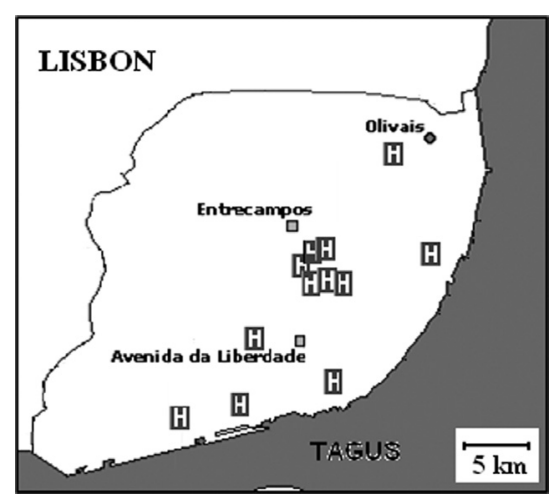

Figure 1. Distribution of the main hospitals and air quality monitoring stations in Lisbon 


\section{Environmental and health data}

Air quality data were obtained from monitoring stations belonging to the Portuguese Environmental Agency, which provide hourly observations for different atmospheric pollutants. Three measuring stations in Lisbon were considered: Avenida da Liberdade, Entrecampos and Olivais. The last one is classified as an urban background station, whereas the other two can be regarded as typical traffic exposed sites. The air quality indicators considered in the analysis were $\mathrm{PM}_{10}(24-\mathrm{h}$ average) and the gaseous pollutants $\mathrm{SO}_{2}$ (24-h average), $\mathrm{NO}$ (maximum 1-h average), $\mathrm{NO}_{2}$ (maximum 1-h average), $\mathrm{CO}$ (maximum 1-h average), and $\mathrm{O}_{3}$ (maximum 1-h average). It was required to have at least $75 \%$ of the 1 -h values on that particular day for the calculation of 24-h averages for $\mathrm{PM}_{10}$ and $\mathrm{SO}_{2}$, as well for the computation of maximum 1-h averages of $\mathrm{NO}, \mathrm{NO}_{2}$ and $\mathrm{CO}$. In the case of $\mathrm{O}_{3}$, it was requested to have at least $75 \%$ of 1 -h values from 6 am until $7 \mathrm{pm}$ for the calculation of maximum 1-h averages for $\mathrm{O}_{3}$, since the maximum $\mathrm{O}_{3}$ levels always occur during daylight time. The pollution values from the three stations were averaged to provide single estimates of the daily concentrations for each pollutant. Missing air pollution data at a monitoring station were replaced by the weighted average of the values of the rest of the monitoring stations. For days with missing values at all monitoring stations, the resulting series also had a missing value, which was replaced by the average of the value of the pollutant of the previous day and the next day. Consecutive days with missing values were not filled in. Figure $2 \mathrm{~S}$ shows temporal features in observed air quality for the studied period.

Note that $\mathrm{PM}_{10}$ concentrations (Table 1) slightly exceed the European and Portuguese (since 2005) standard of $40 \mu \mathrm{g} \mathrm{m}^{-3}$ (based on an average of 3 years). Considering the daily values, which according to the EU and the Portuguese legislation, should not surpass 50 $\mu \mathrm{g} \mathrm{m}^{-3}$ more than 35 times/year, the latter was exceed 98 times/year. The other pollutants under legislation $\left(\mathrm{SO}_{2}, \mathrm{NO}_{2}, \mathrm{CO}\right.$ and $\left.\mathrm{O}_{3}\right)$ have their maxima exceeding the regulated values, but the averages are lower. Except for $\mathrm{O}_{3}$, the atmospheric pollutants reveal a seasonal pattern with high winter levels and low summer loads. Though the air pollution from traffic does not change noticeably from season to season, the increase in concentrations during the cold season might be explained by additional sources only operating in winter, such as heating (e.g. fireplaces and wood stoves). On the other hand, lower winter temperatures promote the decrease of mixing heights and the existence of inversion layers, leading to poorer dispersion and diminishing the dilution factors of pollutants. Ozone peaks during the summer months, when the weather conditions are perfect for its formation. Sunlight, warm temperatures and high emissions of precursor pollutants (nitrogen oxides and volatile organic compounds) lead to high levels of this atmospheric oxidant. Moreover, the mean temperature and humidity values were also calculated for each day from data obtained from the Portuguese Meteorological Institute. The time series of the observed meteorological variables are depicted in Figure 3S.

Table 1. Selected summary statistics for air pollutant concentrations $\left(\mu \mathrm{g} \mathrm{m}^{-3}\right)$

\begin{tabular}{lccccccc}
\hline Variable & mean & $\mathrm{SD}$ & $\min$ & $25 \%$ & $50 \%$ & $75 \%$ & $\max$ \\
\hline $\mathrm{PM}_{10}$ & 43.2 & 20.9 & 10.6 & 28.3 & 43.2 & 53.0 & 207 \\
$\mathrm{SO}_{2}$ & 5.31 & 7.25 & 0.00 & 1.48 & 3.22 & 6.35 & 124 \\
$\mathrm{NO}$ & 132 & 128 & 2.27 & 49.7 & 86.2 & 169 & 972 \\
$\mathrm{NO}_{2}$ & 75.4 & 33.0 & 16.3 & 51.3 & 70.7 & 92.7 & 289 \\
$\mathrm{CO}$ & 1563 & 1384 & 228 & 744 & 1100 & 1796 & 11567 \\
$\mathrm{O}_{3}$ & 60.4 & 26.5 & 4.00 & 41.5 & 59.0 & 76.0 & 190 \\
\hline
\end{tabular}

It is worth noting that Lisbon benefits from the moderating influence of the Atlantic Ocean and of the Gulf Stream, which ensures the lack of extreme temperatures sometimes occurring in central Portugal and Spain. Temperatures show marked seasonality, reaching their maximum in August and minimum in January. In summer, temperatures currently fluctuate between 16 and $30{ }^{\circ} \mathrm{C}$. However, during some weeks of summer 2003, the atmospheric circulation formed an important ridge associated with south-easterly flow, and a strong advection of hot and dry air from northern Africa that was additionally heated when passing over central Iberia. ${ }^{39}$ Meteorological data for the Lisbon region over these periods confirm an abrupt increase in the temperature values, and a significant drop in the relative humidity records. During the study period, the number of days with mean temperatures below $0{ }^{\circ} \mathrm{C}$ (frost days) was nil. On most days, humidity varied in a narrow range around 70 to $80 \%$. In order to analyse the pairwise correlation between air pollution (except for $\mathrm{O}_{3}$ ) and meteorological variables the cross-correlations functions were calculated. In general, the correlations within air pollution variables are in general weak, being the maximum peak (around 0.4) achieved at time delays up to 3 . Moreover, the temperature appears to be negatively correlated with the air pollution variables and the humidity. This might be due to the fact that higher air pollution levels occur during the winter seasons, probably due to the high atmospheric stability and lower mixing depth, which restricts and confine pollutant dispersion.

Health data were acquired from the Institute for Computer and Financial Management of Health Services (IGIF). Daily counts of hospital admissions in 12 institutions were recorded, for the period 1999-2004, for all respiratory causes and for all circulatory diseases - ninth revision of the international classification of diseases (ICD-9 <800): 1) all respiratory causes (ICD-9 460-519), and distributed by asthma (ICD-9 493) and chronic obstructive pulmonary disease, COPD (ICD-9 490-492, 494-496); 2) all circulatory diseases (ICD9 390-459), and distributed by cardiac diseases (ICD-9 390-429), ischemic heart disease (ICD-9 410-414) and stroke (ICD-9 430-438). The 12 hospital institutions had a catchment population covering the entire city. All official data provided by IGIF were already separated into the following age groups: $0-14,15-64$, and $>64$ years old. Table 2 presents key values from summary statistics for cardiorespiratory visits to emergency services.

The high prevalence of asthma, especially among children, reported in various regions around the world was not observed in Lisbon. This may reflect the diffusion of educational measures about the disease to children (and/or their parents), such as the need to limit daily activities to control asthma attacks, the consistent use of medications, and the implementation of low-cost measures for indoor allergen avoidance for reducing the number of sick days and unscheduled visits to health care facilities. ${ }^{40,41}$ Problems with the cardiovascular system are very common and do not just affect older people - many heart and circulatory system problems involve children and teens, too. Heart and circulatory problems are grouped into two categories: congenital, which means the problems were present at birth, and acquired, which means that the problems developed some time during infancy, childhood, adolescence, or adulthood. The increased number of people living with congenital heart disease in developed countries may be due to changing birth prevalence rates related to increasing maternal age or exposure to medication during the first semester of pregnancy. On the other hand, the worldwide rise in childhood obesity is so great that it might lead to an epidemic of premature cardiovascular diseases. Compared to published data on other European countries, Portuguese children show the second highest mean values in overweight/obesity with a prevalence of $31.5 \% .^{42}$ Besides obesity, other risk factors for an increased incidence of cardiovascular diseases in children and adolescents include diabetes mellitus and cigarette smoking. A study 
conducted in 50 countries concluded that Portugal has one of the highest incidences $(\geq 20 / 100,000)$ of childhood type 1 diabetes. ${ }^{43}$ The prevalence of tobacco smoking among young teenagers in Portugal was estimated to be around $40 \%$. In addition, between 30 and $50 \%$ of children are exposed to passive smoking at home. ${ }^{44}$ However, it should be taken into account that the low number of registrations for COPD, asthma and ischemic heart diseases could also be due to the fact that the hospital administrations do not specify to IGIF the type of respiratory or circulatory problem, except when cardiac disease and stroke are diagnosed.

Table 2. Descriptive analysis of the daily number of hospital admissions at the twelve hospitals, for the 1999-2004 period

\begin{tabular}{|c|c|c|c|c|}
\hline Variable & mean & SD & $\min$ & $\max$ \\
\hline All respiratory & 16.95 & 5.21 & 4.00 & 37.00 \\
\hline $0-14$ & 1.57 & 1.44 & 0.00 & 10.00 \\
\hline $15-64$ & 10.59 & 3.84 & 1.00 & 28.00 \\
\hline$>64$ & 4.79 & 2.49 & 0.00 & 17.00 \\
\hline COPD & 1.70 & 1.42 & 0.00 & 8.00 \\
\hline $0-14$ & 0.10 & 0.34 & 0.00 & 4.00 \\
\hline $15-64$ & 1.35 & 1.24 & 0.00 & 8.00 \\
\hline$>64$ & 0.24 & 0.54 & 0.00 & 4.00 \\
\hline Asthma & 0.24 & 0.52 & 0.00 & 3.00 \\
\hline $0-14$ & 0.01 & 0.03 & 0.00 & 1.00 \\
\hline $15-64$ & 0.13 & 0.39 & 0.00 & 3.00 \\
\hline$>64$ & 0.10 & 0.34 & 0.00 & 3.00 \\
\hline All circulatory & 30.79 & 7.79 & 5.00 & 60.00 \\
\hline $0-14$ & 15.64 & 5.21 & 2.00 & 34.00 \\
\hline $15-64$ & 9.587 & 3.88 & 0.00 & 26.00 \\
\hline$>64$ & 5.559 & 2.67 & 0.00 & 17.00 \\
\hline Cardiac & 24.15 & 6.85 & 4.00 & 52.00 \\
\hline $0-14$ & 14.64 & 5.05 & 2.00 & 33.00 \\
\hline $15-64$ & 5.09 & 2.84 & 0.00 & 18.00 \\
\hline$>64$ & 4.42 & 2.36 & 0.00 & 15.00 \\
\hline Ischemic heart & 1.59 & 1.73 & 0.00 & 12.00 \\
\hline $0-14$ & 0.05 & 0.20 & 0.00 & 2.00 \\
\hline $\begin{array}{l}0-14 \\
15-64\end{array}$ & 0.96 & 1.27 & 0.00 & 9.00 \\
\hline$>64$ & 0.58 & 0.87 & 0.00 & 6.00 \\
\hline Stroke & 1.99 & 1.50 & 0.00 & 9.00 \\
\hline $0-14$ & 0.17 & 0.46 & 0.00 & 4.00 \\
\hline $15-64$ & 1.62 & 1.35 & 0.00 & 8.00 \\
\hline$>64$ & 0.20 & 0.45 & 0.00 & 2.00 \\
\hline
\end{tabular}

\section{Statistical analysis}

Hospital admissions reflect counts which are usually modelled with a Poisson or overdispersed Poisson distribution. ${ }^{30,45-49}$ Here, $Y_{i}$ will signify the number of hospital admissions for day $i=1,2, \ldots, n . X$ $=\left[x_{1}, \ldots, x_{p}\right]$ denotes the $(n \mathrm{x} p)$ design matrix based on all covariates under consideration being $x_{j}=\left[x_{j ; 1}, \ldots, x_{j ; i} ; \ldots ; x_{j ; n}\right]^{T}$. The design matrix $X$ can include basic terms for smoothing splines to model nonlinear trends, meteorological and pollution variables, seasonal and weekly indicators, among others. A suitable way of modelling non-Gaussian response variables, such as these, is through the use of Generalised Linear Models (GLMs) or Generalised Additive Models (GAMs), which are flexible enough to include a wide range of common situations, but at the same time, allow most of the familiar ideas of normal linear regression to carry over. ${ }^{50}$ In the following paragraphs, some important aspects related with GLMs and GAMs are briefly sketched.
GLMs describe the dependence of a response variable $Y_{i}$ on a set of regressors $X$. The conditional distribution of $Y_{i} \mid x^{(i)}$, with $x^{(i)}=$ $\left(x_{1, i}, \ldots, x_{p, i}\right)$ representing the vector of covariates on day $i$ is a linear exponential family density function

$$
f(y ; \lambda, \phi)=\exp \left(\frac{y \lambda-b(\lambda)}{\phi}+c(y, \phi)\right)
$$

where $\lambda$ is the canonical parameter that depends on the regressors via a linear predictor and $\phi$ is a dispersion parameter that is often known. The functions $b(\cdot)$ and $c(\cdot)$ are known and determine which member of the family is used, e.g., the binomial or Poisson distribution. Conditional mean and variance of $Y_{i}$ are given by $E\left[Y_{i} \mid x^{(i)}\right]$ $=\mu_{i}=b^{\prime}\left(\lambda_{i}\right)$ and $V\left[Y_{i} \mid x^{(i)}\right]=\phi b^{\prime \prime}\left(\lambda_{i}\right)$, where $b^{\prime}\left(\lambda_{i}\right)$ and $b^{\prime \prime}\left(\lambda_{i}\right)$ are the first and second derivative with respect to $\lambda_{i}$ of $b(\cdot)$. In the GLMs, it is assumed that the dependence of the conditional mean $\mu_{i}$ on the regressors $X^{(i)}$ is specifed via

$$
g\left(\mu_{i}\right)=x^{(i)} \beta=\beta_{0}+\sum_{j=1}^{p} \beta_{j} x_{j, i}
$$

where $g(\cdot)$ is a known link function and $\beta$ is the vector of regression coefficients which are typically estimated by maximum likelihood using the iterative weighted least squares algorithm. For the Poisson distribution the link function is given by

$$
g\left(\mu_{i}\right)=\log \left(\mu_{i}\right)=\beta_{0}+\sum_{j=1}^{p} \beta_{j} x_{j, i}
$$

resulting in a log-linear relationship between mean and the regressors. The variance of the Poisson model is identical to the mean, thus the dispersion parameter is fixed at $\phi=1$. In practice, however, the Poisson model is often useful for describing the mean $\mu$, but underestimates the variance in the data, rendering all model-based tests liberal. One way of dealing with this is to use the mean regression function and the variance from the Poisson GLM, but to leave the dispersion parameter $\phi$ unrestricted. Thus, $\phi$ is not assumed to be fixed at one but is estimated from the data. This strategy leads to the same coefficient estimates as the standard Poisson model, but inference is adjusted for overdispersion. In addition to overdispersion, many empirical count data sets exhibit more zero observations than would be allowed for by the Poisson model. This problem is tackled by making use of various zero-inflated regression models that have been suggested in the literature. ${ }^{51,52}$ Zero-inflated count models are basically two-component mixture models combining a point mass at zero with a count distribution such as Poisson, geometric or negative binomial. Thus, there are two sources of zeros: zeros may come from both the point mass and from the count component. For modelling the unobserved state (zero vs. count), a binary model is used: in the simplest case only with an intercept but potentially containing regressors. It is important to stress that the usefulness of Poisson regression in epidemiology relies on the fact that it provides an estimation of the relative risk (RR) as $\mathrm{RR}_{i}=\exp \left(\beta_{i}\right)$, being $\beta_{i}$ the regression coefficients associated with an unit increment in a pollutant. To calculate the RRs associated with an increment of $10 \mu \mathrm{g} \mathrm{m}^{-3}$ in the pollutant concentration, then $\mathrm{RR}_{i}$ $=\exp \left(\beta_{i} \times 10\right)$, and the percentage increase in the number of patients admitted to hospital emergencies will be $\%=\left(R_{\mathrm{i}}-1\right) \times 100$.

GAMs extend the GLMs by fitting nonparametric functions (see $h_{j}(\cdot)$ below) to estimate the relationship between the response variable and the regressors

$$
\log \left(\mu_{i}\right)=h_{0}+\sum_{j=1}^{p} h_{j}\left(x_{j, i}\right)
$$

Methods for estimating $h(\cdot)$ include smoothing splines or LOESS smoothers. Estimation in GAMs is based on the combination of the 
local scoring algorithm and the backfitting algorithm. The local scoring algorithm is a generalisation of the Fisher scoring procedure for finding maximum likelihood estimates in GLMs. The backfitting algorithm is suitable for fitting any additive model, and in GAMs it is used within the local scoring iteration when several smooth functions are included in the model. ${ }^{53}$

An important assumption of any regression analysis is that the residuals must be uncorrelated. Since in epidemiological studies, however, the data are collected over time, it is likely that the response variable presents some serial dependence. Residual serial correlation can imply confounding of air pollution associations due to unmeasured or mismodelled variables. In fact, if the inclusion of known or potential confounders fails to remove the serial correlation of the residuals, then it is known that the estimation procedures does not provide valid estimates of the standard errors of the parameters. For example, the relationship between daily mortality and weather temperature presents the typical $V$-shape.$^{54}$ Low environmental temperatures imply high mortality, whereas high weather temperatures are also related to high mortality. Increasing temperature up to a certain point, however, reduces mortality. If the regression does not account for this fact, positive residuals will be followed by other positive residuals and the same occurs with negative residuals. Thus, in time series regression one can use conventional regression methods followed by a check for the serial correlation of the residuals and need only proceed further if there is clear evidence of lack of independence.

In this study, when applying GAMs, linear and quadratic tendency terms were included to control the confounding seasonal effect. Dummy variables for years and weekday were also considered. Air pollutant variables were modelled through cubic smoothing splines (hereafter denoted by $(s)$ ). ${ }^{55}$ The choice of the number of degree of freedom (df) for the non-parametric smoothing functions was made on the basis of minimisation of the Akaike's Information Criteria (AIC), the observed residual AutoCorrelation Function (ACF) and the Partial AutoCorrelation Function (PACF) plots, as well as using cross-validation of predicted values. ${ }^{56,57}$ Moreover, in order to control for unobserved covariates with systematic behaviour, dummy variables for years and days of the week were also considered. Other covariates considered were temperature and humidity. Furthermore, it is also important to allow for time lags of the air pollutants variables. ${ }^{58}$ Pollution levels may affect health many days after an episode or several days will be required for pollutants to build up to their maximum effect. In fact, short-term health outcomes caused by pollution seem to follow a lagged pattern where biological manifestations take a time lag to develop after exposure to pollutants. This means that emergency room admissions recorded at a given day can be associated with the level of air pollution on that same day as well as to that of preceding days. For more accurately defining the model to be used in the analysis, it is crucial to determine an optimal lag structure. Thus, constrained distributed lag models adjusted for long trend, weekdays, etc., were used to assess the lagged effects of exposure. After a core model is best-fitted, the current value and up to four lags for each air pollutant variables are included according with their individual level of statistical significance by means of the stepwise procedure, and jointly on the basis of those that minimised AIC. An important issue which sometimes arises in this kind of analysis is the possibility that residuals may be serially correlated. A standard method to decide whether residuals are correlated or not is by means of the visual inspection of the ACF and the PACF graphs. This is also the method adopted in the present analysis. For all cases, the assumption of uncorrelated residuals is teneable. The statistical analysis was conducted with the use of the statistical package $\mathrm{R}$ (http://cran.r-project.org) using restrictive convergence parameters as suggested by Dominici et al.. ${ }^{59}$

\section{RESULTS AND DISCUSSION}

This section presents the results obtained by fitting GAM models to evaluate the effects of the air pollutants on the daily number of admissions separated by age groups. Due to the low number of registrations in some of the respiratory causes and circulatory diseases, for COPD and stroke, only the age group 15-64 years is included in the analysis, whereas for IHD only the age groups 15-64 and >64 years are examined. The assumptions of non-serially correlation and non-overdispersion are tenable for all cases. Table 3 presents the model regression coefficients for the best fitted GAMs for the various diseases.

Sulphur dioxide was found to be significantly related to emergency room admissions for all respiratory diseases among children. By fitting the model, it was estimated that the risk for respiratory diseases among children increased by $14 \%(\mathrm{RR}=1.139)$ with $95 \%$ confidence interval $(12.6,15.4 \%)$, for an increase of $10 \mu \mathrm{g} \mathrm{m}^{-3}$ of $\mathrm{SO}_{2}$ daily concentrations. In this study, the generalised additive models did not reveal any statistically significant association between other pathologies among either the youngest age group or all the diseases for other population groups and the $\mathrm{SO}_{2}$ atmospheric levels. It is worth to stress that previous findings regarding the association between $\mathrm{SO}_{2}$ and hospital emergency visits have been inconsistent, because in some studies the pollutant was not significantly associated with cardiorespiratory diseases but other studies have reported positive relationships. Segala et al. ${ }^{60}$ in Paris, Atkinson et al ${ }^{61}$ in London, and Sunyer et al. ${ }^{33}$ in the cities of Birmingham, London, Milan, Paris, Rome, Stockholm, and in the Netherlands, associated $\mathrm{SO}_{2}$ with visits to the emergency departments. In contrast, studies performed in Madrid, ${ }^{62}$ Rome $^{30}$ and Valencia ${ }^{63}$ found no relationship between $\mathrm{SO}_{2}$ and the hospital admissions for asthma. In Lisbon, repercussion on respiratory diseases among children occurred with delay of only 1-day, which could be explained by the direct effect of $\mathrm{SO}_{2}$ on the smooth muscle or via sensory afferent nerve fibres that cause reflex bronchoconstriction. ${ }^{64}$ In addition, $\mathrm{SO}_{2}$ reacts with other chemicals in the air to form tiny sulphate particles. When these are breathed, they gather in the lungs and are associated with increased respiratory symptoms and with a decrease in the ability of the lungs to clear foreign particles and bacteria. ${ }^{24}$ Short time effects were also observed in Puertollano and Ciudad Real, Spain. ${ }^{64}$

A negative, but statistically significant, effect of ozone at a 2-day lag was observed on the respiratory health of children and elderly people. A slightly negative, but significant, association was also established between previous day ozone levels and all circulatory and cardiac outcomes for all three age groups. Several investigations have shown that high concentrations of ozone are harmful to some people and have shown a positive association between $\mathrm{O}_{3}$ and hospital admissions. ${ }^{5,16,23,29,32,48,64}$ However, some published studies found that, sometimes at low ambient $\mathrm{O}_{3}$ levels, the relationship between various measures of morbidity and ozone concentration has a negative slope, that is, low levels of ozone appear to be more harmful than moderate values. ${ }^{65-67}$ Revising the literature, Ritchie and Lenen ${ }^{66}$ refer that no statistically significant effect for $\mathrm{O}_{3}$ and various respiratory conditions was reported in studies undertaken in Hong Kong, London, Melbourne, Mexico, southern Ontario, Seattle, Sidney, St. John (New Brunswick), and Vancouver. The same authors found a statistically significant negative association for asthma and no relationship for other respiratory diseases on children in the Indianapolis Metropolitan Area. Since there is no evidence that low levels of ozone are intrinsically harmful, this association seems paradoxical. Paradoxical ozone associations could be due to methyl nitrite from combustion of methyl ethers or esters in engine fuels. ${ }^{68}$ Methyl nitrite is known to be highly toxic, and closely related alkyl nitrites are known to induce 
Table 3. Model regression coefficients and their standard error for the best-fitted GAM model, corresponding relative risk and percentage of increase in the number of emergency admissions per $10 \mu \mathrm{g} \mathrm{m}^{-3}$ increase in levels of pollutants

\begin{tabular}{|c|c|c|c|c|c|c|c|c|c|c|}
\hline & $\phi$ & Residuals df & AIC & Lag & Coefficient $(\beta)$ & Standard error & t-statistic & p-value & $\mathrm{RR}$ & $\%$ increase \\
\hline \multicolumn{11}{|c|}{$<15$ years old - all respiratory causes } \\
\hline Intercept & & & & & 0.304 & 0.066 & 4.587 & $<0.01$ & & \\
\hline $\mathrm{s}\left(\mathrm{SO}_{2}\right)$ & & & & 1 & 0.013 & 0.002 & 5.312 & $<0.01$ & 1.1388 & 13.9 \\
\hline \multirow[t]{2}{*}{$\mathrm{s}\left(\mathrm{O}_{3}\right)$} & & & & 2 & -0.003 & 0.0007 & -3.761 & $<0.01$ & 0.9704 & -2.96 \\
\hline & 1.13 & 1770 & 5759 & & & & & & & \\
\hline \multicolumn{11}{|c|}{$>64$ years old - all respiratory causes } \\
\hline Intercept & & & & & 2.490 & 0.160 & 15.476 & $<0.01$ & & \\
\hline $\mathrm{s}(\mathrm{CO})$ & & & & 2 & $2.73 e-05$ & $8.03 \mathrm{e}-06$ & 3.403 & $<0.01$ & 1.0003 & 0.03 \\
\hline \multirow[t]{2}{*}{$\mathrm{s}\left(\mathrm{O}_{3}\right)$} & & & & 2 & -0.0010 & $4.85 \mathrm{e}-04$ & -2.904 & $<0.01$ & 0.9900 & -1.00 \\
\hline & 1.15 & 1801 & 8222 & & & & & & & \\
\hline \multicolumn{11}{|c|}{$<15$ years old - all circulatory causes } \\
\hline Intercept & & & & & 3.2155 & 0.1501 & 21.424 & $<0.01$ & & \\
\hline $\mathrm{s}\left(\mathrm{NO}_{2}\right)$ & & & & 3 & 0.0008 & 0.0033 & 2.657 & $<0.01$ & 1.0080 & 0.80 \\
\hline $\mathrm{s}(\mathrm{CO})$ & & & & 2 & $<10^{-5}$ & $<10^{-6}$ & -3.368 & $<0.01$ & 1.0001 & 0.01 \\
\hline $\mathrm{s}\left(\mathrm{O}_{3}\right)$ & & & & 1 & -0.0008 & 0.0003 & -2.492 & 0.01 & 0.9920 & 0.01 \\
\hline \multirow[t]{2}{*}{ s(Temp.) } & & & & & 0.0099 & 0.0017 & 5.753 & $<0.01$ & & \\
\hline & 1.11 & 896 & 51274 & & & & & & & \\
\hline \multicolumn{11}{|c|}{ 15-64 years old - all circulatory causes } \\
\hline Intercept & & & & & 2.8803 & 0.1871 & 15.392 & $<0.01$ & & \\
\hline $\mathrm{s}\left(\mathrm{NO}_{2}\right)$ & & & & 3 & 0.0005 & 0.0002 & 2.150 & 0.031 & 1.0050 & 0.50 \\
\hline $\mathrm{s}\left(\mathrm{O}_{3}\right)$ & & & & 1 & -0.0011 & 0.0003 & -2.995 & $<0.01$ & 0.9891 & -1.09 \\
\hline \multirow[t]{2}{*}{ s(Temp.) } & & & & & 0.0171 & 0.0021 & 7.943 & $<0.01$ & & \\
\hline & 1.23 & 1782 & 9661 & & & & & & & \\
\hline \multicolumn{11}{|c|}{$>64$ years old - all circulatory causes } \\
\hline Intercept & & & & & 2.542 & 0.2220 & 11.448 & $<0.01$ & & \\
\hline $\mathrm{s}\left(\mathrm{NO}_{2}\right)$ & & & & 3 & 0.0022 & 0.0004 & 5.233 & $<0.01$ & 1.0222 & 2.22 \\
\hline $\mathrm{s}(\mathrm{CO})$ & & & & 2 & $<-10^{-5}$ & $<10^{-5}$ & -3.052 & $<0.01$ & 1.0000 & 0.00 \\
\hline \multirow[t]{2}{*}{$\mathrm{s}\left(\mathrm{O}_{3}\right)$} & & & & 1 & -0.0017 & 0.0005 & -3.303 & $<0.01$ & 0.9831 & -1.69 \\
\hline & 1.09 & 1768 & 8356 & & & & & & & \\
\hline \multicolumn{11}{|c|}{$<15$ years old - cardiac diseases } \\
\hline Intercept & & & & & 2.880 & 0.0410 & 70.24 & $<0.01$ & & \\
\hline $\mathrm{s}\left(\mathrm{NO}_{2}\right)$ & & & & 3 & 0.0012 & 0.0002 & 6.00 & $<0.01$ & 1.0121 & 1.21 \\
\hline $\mathrm{s}(\mathrm{CO})$ & & & & 1 & $<-10^{-5}$ & $<10^{-5}$ & -2.86 & $<0.01$ & 1.0001 & 0.01 \\
\hline$\left(\mathrm{sO}_{3}\right)$ & & & & 1 & -0.0010 & 0.0003 & -3.33 & $<0.01$ & 0.9900 & -1.00 \\
\hline \multirow[t]{2}{*}{ s(Temp.) } & & & & & 0.0090 & 0.0015 & 6.00 & $<0.01$ & & \\
\hline & 1.13 & 1742 & 10217 & & & & & & & \\
\hline \multicolumn{11}{|c|}{ 15-64 years old - cardiac diseases } \\
\hline Intercept & & & & & 2.208 & 0.2326 & 9.49 & $<0.01$ & & \\
\hline $\mathrm{s}\left(\mathrm{NO}_{2}\right)$ & & & & 3 & 0.0012 & 0.0004 & 3.00 & $<0.01$ & 1.0121 & 1.21 \\
\hline $\mathrm{s}(\mathrm{CO})$ & & & & 1 & $<-10^{-5}$ & $<10^{-5}$ & -2.58 & $<0.01$ & 1.0000 & 0.00 \\
\hline $\mathrm{s}\left(\mathrm{O}_{3}\right)$ & & & & 1 & -0.0015 & 0.0005 & -3.00 & $<0.01$ & 0.9851 & -1.49 \\
\hline \multirow[t]{3}{*}{ s(Temp.) } & & & & & 0.0132 & 0.0029 & 4.55 & $<0.01$ & & \\
\hline & 1.23 & 1785 & 8381 & & & & & & & \\
\hline & \multicolumn{10}{|c|}{$>64$ years old - cardiac diseases } \\
\hline Intercept & & & & & 2.066 & 0.1113 & 18.56 & $<0.01$ & & \\
\hline $\mathrm{s}\left(\mathrm{NO}_{2}\right)$ & & & & 3 & 0.002 & 0.0004 & 5.69 & $<0.01$ & 1.0202 & 2.02 \\
\hline $\mathrm{s}(\mathrm{CO})$ & & & & 2 & $<-10^{-5}$ & $<10^{-5}$ & -3.78 & $<0.01$ & 1.0000 & 0.00 \\
\hline $\mathrm{s}\left(\mathrm{O}_{3}\right)$ & & & & 1 & -0.002 & $<10^{-5}$ & -3.58 & $<0.01$ & 0.9802 & -1.98 \\
\hline \multirow[t]{2}{*}{ s(Temp.) } & & & & & 0.011 & 0.0028 & 4.00 & $<0.01$ & & \\
\hline & 1.09 & 1790 & 7871 & & & & & & & \\
\hline
\end{tabular}


respiratory sensitivity in humans. ${ }^{69}$ Given that sunlight is essential to create ozone by photochemical oxidation, a probable explanation for the paradoxical ozone associations would be the existence of this nitrite pollutant that is rapidly destroyed by solar radiation. ${ }^{6}{ }^{6}$ Hence, methyl nitrite is negatively correlated with $\mathrm{O}_{3}$. Days with low solar radiation are likely to be days with both low ozone and high methyl nitrite, so that low ozone would be a marker for low solar radiation and high methyl nitrite. Because sunlight has opposing effects on ozone and methyl nitrite, one would expect the most acute methyl nitrite effects in winter. ${ }^{68}$

In Lisbon, daily emergency admissions for all respiratory causes showed a statistically significant positive association with $\mathrm{CO}$ at a 2-day lag for patients aged above 64 years (Table 3). A similar relationship was established between the pollutant and the number of daily emergencies due to all circulatory symptoms for children less than 15 years of age and elderly people. For all age groups, daily levels of $\mathrm{CO}$ were significant and positively associated with cardiac disease. For children $(<15)$ and adults $(15-64$ years old) there was a 1-day delayed effect of $\mathrm{CO}$, while a 2-day late outcome was observed for elderly people. Since the effects of $\mathrm{CO}$ exposure associated with hypoxic stress are in general felt immediately after inhalation, it was postulated that a toxic mechanism besides hypoxia might be involved. It was observed that exposure of blood platelets to relatively low levels of $\mathrm{CO}$ caused the cells to release nitric oxide and to produce peroxynitrite, which produces oxidative stress and is known to damage the vascular endothelium. ${ }^{70}$ Carbon monoxide has been related to respiratory and cardiovascular conditions in several investigations. ${ }^{30,31}$ However, in spite of recent epidemiological and biochemical studies, the effects on health of long-lasting but low level exposure to $\mathrm{CO}$ are still uncertain. A more careful examination of the role of this pollutant would be desirable, since it is also known that ambient $\mathrm{CO}$ could precipitate or exacerbate already existing health conditions.

In the present study, the GAMs fitted show a statistically significant positive association at a 3-day lag between $\mathrm{NO}_{2}$ levels and total circulatory and cardiac conditions in all age groups. No significant association between the pollutant and respiratory morbidity has been found. According to the models, the risk for circulatory diseases increased by $0.8 \%(0.793,0.807 \%), 0.5 \%(0.49,0.51 \%)$ and $2.2 \%$ $(2.19,2.21 \%)$ per $10 \mu \mathrm{g} \mathrm{m}^{-3}$ increase in daily levels of $\mathrm{NO}_{2}$ for the $<15,15-64$, and $>64$ age groups, respectively. The same unit change in the pollutant increases the risk by $1.2 \%(1.18,1.22)$ and $2.0 \%$ $(1.19,2.1 \%)$ among nonelderly and elderly people, respectively. Although $\mathrm{NO}_{2}$ has been known to increase susceptibility to respiratory infections, results of different studies that looked at the link between $\mathrm{NO}_{2}$ and respiratory outcomes still show discrepancies. For instance, Spix et al..$^{71}$ observed no significant relationship between $\mathrm{NO}_{2}$ and respiratory admissions for the 15-64 and >64 year age groups from five West European cities (London, Amsterdam, Rotterdam, Paris, and Milan). Atkinson et al. ${ }^{61}$ reported no significant associations between $\mathrm{NO}_{2}$ and respiratory admissions in London overall or within any of three age groups $(0-14,15-64$, and $>64$ years $)$. A lack of associations between $\mathrm{NO}_{2}$ and hospital admissions in Paris for respiratory diseases was also observed by Dab et al. ${ }^{72}$ In contrast, Wong et al. ${ }^{73}$ reported significant associations between $\mathrm{NO}_{2}$ and respiratory admissions for $0-4,5-64$ and $\geq 65$ year age groups in Hong Kong. Luginaah et al. ${ }^{74}$ found a significant association between levels of $\mathrm{NO}_{2}$ lagged 2-days and respiratory admissions for females 0-14 years of age, but not for any of the other female or male groups.

In Lisbon, no significant correlation between $\mathrm{PM}_{10}$ and health conditions was found. Time-series analysis conducted in the scope of the "Air Pollution and Health, European Approach" (APHEA) project $^{75}$ and within other epidemiological studies in Europe ${ }^{30,63}$ have suggested that gaseous air pollutants, in particular $\mathrm{CO}$ and $\mathrm{NO}_{2}$, are more important predictors of acute hospitalisation for respiratory conditions than particulate matter. The fact that European studies seem to show more $\mathrm{NO}_{2} / \mathrm{CO}$ effects than US studies deserves additional investigation. Because of different combustion sources, it may be that $\mathrm{NO}_{2} / \mathrm{CO}$ are better proxies for ultrafine particles in Europe, where there is a greater use of diesel, than in the USA.$^{30}$ In fact, particulates pose greater problems, since the biological effect can be influenced by particle size and composition. It is also possible that $\mathrm{PM}_{10}$ is itself a by-product of some chemical reactions involving other pollutants and that these precursors are the real cause of morbidity.

Among the meteorological variables recorded, significant positive association was found only between temperature and attendance for all circulatory and cardiac diseases among all age groups (Table 3), indicating that higher ambient temperatures could generate higher rates of hospital admissions. The nature and magnitude of the association between temperature and human health has been increasingly recognised and the physiological effects of hyperthermia are well known. ${ }^{76,77}$

It should be mentioned that numerous methodological factors restrain the comparability and power of the various studies, including: (i) absence of measurement of additional atmospheric compounds with possible biological effect (e.g. benzene and sulphate), besides the traditional air pollutants; (ii) difficulty of comparing risks for particles of different aerodynamic diameter which do not have the same health impact, especially on the respiratory tract; (iii) extrapolation of measurements performed by fixed monitors which do not take into account the movement of persons nor the level of indoor air quality, (iv) assessment of daily average levels of air pollutants instead time-period peaks, which may produce more adverse effects; and (v) difficulty of evaluating the interaction of pollutants with confounding factors, such as viral infections or smoking. We did not adjust the result for cigarette smoking simply because data on tobacco consumption were not available. There are both spatial and temporal variations for exposure and outcomes in air pollution studies. Both time series and case-crossover designs at a community level can efficiently adjust for some measured and unmeasured timeinvariant characteristics of the subjects (such as age, smoking status and spatial characteristics) via matching, and therefore, the potential confounding from these measured and unmeasured characteristics is minimised. ${ }^{78}$ In fact, human health impacts of acute exposure to air pollution problems associated with confounding factors are reduced in these studies because population characteristics, such as smoking, do not change much over the study period. ${ }^{79}$ In spite of the limitations of this study, atmospheric pollution in Lisbon appears to lead to poorer clinical outcomes in patients with respiratory and cardiocirculatory diseases. In the broader context of environmental guidelines, it is regularly discussed that where there is reasonable substantiation of an adverse health effect, authorities should take action ahead of the evidence to become assured.

\section{CONCLUSIONS}

Air pollution levels in Lisbon are capable of producing harmful effects in the health of the population. A significant association between $\mathrm{SO}_{2}$ and increased childhood emergency admissions for respiratory illness was showed. Significant associations between circulatory and cardiac diseases for all age groups and proxy markers of road traffic pollution $\left(\mathrm{NO}_{2}\right.$ and $\left.\mathrm{CO}\right)$ were also found. High excess relative risk of emergency daily morbidity associated with the short-term exposure to air pollutants, especially for those considered more susceptible, point out the need for adoption of mitigation measures. The reported associations, together with the results of studies performed in the United States and in European 
regions add to the evidence that air pollution promotes adverse effects on cardiorespiratory health even when pollutant levels are lower than the air quality standards. These results suggest that air quality standards less than the current values would be needed to avoid any adverse health effects among the general population. In addition, stricter control at source, whether by transport policies, support policies for efficient municipal heating systems, or regulatory changes, should decrease the concentrations of the main atmospheric pollutants and thus reduce morbidities. It would be prudent public attentiveness of the alert situations. By taking suitable measures, the risk for cardiorespiratory patients could be reduced.

\section{SUPPLEMENTARY MATERIAL}

Additional information concerning the temporal variation of air pollutant concentrations and meteorological parameters is available free of charge at http://quimicanova.sbq.org.br, as a PDF file.

\section{ACKNOWLEDGEMENTS}

The authors express their gratitude to the Portuguese Environmental Agency, Institute for Computer and Financial Management of Health Services, and Meteorological Institute for providing the time series data. This investigation was performed within the project POCI/ AMB/55878/2004 (Atmospheric aerosol impacts on human health).

\section{REFERENCES}

1. Utell, M. J.; Frampton, M. W.; Inhal. Toxicol. 2000, 12 (Suppl 1), 37.

2. Kelly, F. J.; Dunster, C.; Mudway, I.; Eur. Respir. J. 2003, 21, 70S.

3. Dominici, F.; Peng, R. D.; Bell, M. L.; Pham, L.; McDermott, A.; Zeger, S. L.; Samet, J. M.; J. Am. Med. Assoc. 2006, 295, 1127.

4. Fung, K. Y.; Luginaah, I. N.; Gorey, K. M.; Environ. Health 2007, 6, 18.

5. Jaffe, D. H.; Singer, M. E.; Rimm, A. A.; Environ. Res. 2003, 91, 21.

6. Lin, M.; Stieb, D. M.; Chen, Y.; Pediatrics 2005, 116, e235.

7. Linn, W. S.; Szlachcic, Y.; Gong, H.; Kinney, P. L.; Berhane, K. T.; Environ. Health Persp. 2000, 108, 427.

8. Mann, J. K.; Tager, I. B.; Lurmann, F.; Segal, M.; Quesenberry, C. P.; Lugg, M. M.; Shan, J.; Eeden, S. K.; Environ. Health Persp. 2002, 110, 1247.

9. Schwartz, J.; Epidemiology 1999, 10, 17.

10. Symons, J. M.; Wang, L.; Guallar, E.; Howell, E.; Dominici, F.; Schwab, M.; Ange, B. A.; Samet, J.; Ondov, J.; Harrison, D.; Geyh, A.; Am. J. Epidemiol. 2006, 164, 421.

11. Ulirsch, G. V.; Ball, L. M.; Kaye, W.; Shy, C. M.; Lee, C. V.; CrawfordBrown, D.; Symons, M.; Holloway, T.; J. Expo. Sci. Environ. Epidemiol. 2007, 17, 478.

12. Wellenius, G.; Schwartz, J.; Mittleman, M. A.; Am. J. Cardiol. 2006, 7, 404.

13. Brilhante, O. M.; Tambellini, A. M. T.; Int. J. Environ. Health Res. 2002, $12,169$.

14. Farhat, S. C. L.; Paulo, R. L. P.; Shimoda, T. M.; Conceição, G. M. S.; Lin, C. A.; Braga, A. L. F.; Warth, M. P. N.; Saldiva, P. H. N.; Braz. J. Med. Biol. Res. 2005, 38, 227.

15. Santos, U. P.; Terra-Filho, M.; Lin, C. A.; Pereira, L. A. A.; Vieira, T. C. B.; Saldiva, P. H. N.; Braga, A. L. F.; Braz. J. Epidemiol. Commun. Health 2008, 62, 267.

16. Moura, M.; Junger, W. L.; Azevedo, G.; Mendonça, S.; Leon, A. P.; Rev. Saúde Pública 2008, 42, 503.

17. Chan, C. C.; Chuang, K. J.; Chien, L. C.; Chen, W. J.; Chang, W. T.; Eur. Heart J. 2006, 27, 1238.

18. Chang, C. C.; Tsai, S. S.; Ho, S. C.; Yang, C. Y.; Environ. Res. 2004, 98, 114.

19. Cho, B.; Choi, J.; Yum, Y. T.; J. Occup. Health 2000, 42, 185.

20. Joseph, A. E.; Sawant, A.; Srivastava, A.; Int. J. Environ. Health Res. 2003, 13, 207.
21. Ko, F. W. S.; Tam, W.; Wong, T. W.; Chan, D. P. S.; Tung, A. H.; Lai, C. K. W.; Hui, D. S. C.; Thorax 2007, 62, 780.

22. Lee, I. M.; Tsai, S. S.; Chang, C. C.; Ho, C. K.; Yang, C. Y.; Inhal. Toxicol. 2007, 19, 393.

23. Erbas, B.; Kelly, A. M.; Physick, B.; Code, C.; Edwards, M.; Int. J. Environ. Health Res. 2005, 15, 11.

24. Alves, C.; Ferraz, M. C. A.; Int. J. Environ. Pollut. 2005, 23, 43.

25. Anderson, H. R.; Atkinson, R. W.; Bremner, S. A.; Marston, L.; Eur. Resp. J. 2003, 21, 39s.

26. Ballester, F.; Rodriguez, P.; Iniguez, C.; Saez, M.; Daponte, A.; Galan, I.; Taracido, M.; Arribas, F.; Bellido, J.; Cirarda, F. B.; Cañada, A.; Guillén J. J.; Guillén-Grima, F.; López, E.; Pérez-Hoyos, S.; Lertxundi, A.; Toro, S.; J. Epidemiol. Commun. Health 2006, 60, 328.

27. Ballester, F.; Tenias, J. M.; Pérez-Hoyos, S.; J. Epidemiol. Commun. Health 2001, 55, 57.

28. Bedeschi, E.; Campari, C.; Candela, S.; Collini, G.; Caranci, N.; Frasca, G.; Galassi, C.; Francesca, G.; Vigotti, M. A.; J. Toxicol. Environ. Health A 2007, 70, 261.

29. Díaz, J.; García, R.; Ribera, P.; Alberdi, J. C.; Hernández, E.; Pajares, M. S.; Otero, A.; Int. Arch. Occup. Environ. Health 1999, 72, 366.

30. Fusco, D.; Forastiere, F.; Michelozzi, P.; Spadea, T.; Ostro, B.; Arca, M.; Perucci, C. A.; Eur. Resp. J. 2001, 17, 1143.

31. Migliaretti, G.; Dalmasso, P.; Gregori, D.; Int. J. Environ. Health Res. 2007, 17, 369 .

32. Oftedal, B.; Nafstad, P.; Magnus, P.; Bjørkly, S.; Skrondal, A.; Eur. J. Epidemiol. 2003, 18, 671.

33. Sunyer, J.; Atkinson, R.; Ballester, F.; Tertre, A.; Ayres, J.; Forastiere, F.; Forsberg, B.; Vonk, J.; Bisanti, L.; Anderson, R.; Schwartz, J.; Katsouyanni, K.; Occup. Environ. Med. 2003, 60, e2.

34. Sunyer, J.; Ballester, F.; Tertre, A.; Atkinson, R.; Ayres, J. G.; Forastiere, F.; Forsberg, B.; Vonk, J. M.; Bisanti, J.; Tenías, J. M.; Medina, S.; Schwartz, J.; Katsouyanni, K.; Eur. Heart J. 2003, 24, 752.

35. Tertre, A.; Medina, S.; Samoli, E.; Forsberg, B.; Michelozzi, P.; Boumghar, A.; Vonk, J. M.; Bellini, A.; Atkinson, R.; Ayres, J. G.; Sunyer, J.; Schwartz, J.; Katsouyanni, K.; J. Epidemiol. Commun. Health 2002, 56, 773.

36. Mauderley, J. L.; Samet, J. M.; Environ. Health Persp. 2009, 111, 1.

37. Chen, L.; Verrall, K.; Tong, S.; Int. J. Environ. Health Res. 2006, 16, 181.

38. Petroeschevsky, A.; Simpson, R. W.; Thalib, L.; Rutherford, S.; Arch. Environ. Health 2001, 56, 37.

39. Pereira, M. G.; Trigo, R. M.; Câmara, C. C.; Pereira, J. M. C.; Leite, S. L.; Agr. Forest Meteorol. 2005, 129, 11.

40. Castel-Branco, M. G.; Rev. Port. Clin. Geral 2004, 20, 589.

41. Direcção-Geral de Saúde; Programa Nacional de Controlo da Asma, DGS: Lisboa, 2000.

42. Padez, C.; Fernandes, T.; Mourão, I.; Moreira, P.; Rosado, V.; Am. J. Hum. Biol. 2004, 16, 670

43. Karvonen, M.; Viik-Kajander, M.; Moltchanova, E.; Libman, I.; Laporte, R.; Tuomilehto, J.; Diabetes Care 2000, 23, 1516.

44. Rios, S.; Rosas, M.; Machado, P. P. P.; Int. J. Health Psychol. 2005, 5, 143.

45. Braga, A. L. F.; Conceição, G. M. S.; Pereira, L. A. A.; Kishi, H. S.; Pereira, J. C. R.; Andrade, M. F.; Gonçalves, F. L. T.; Saldiva, P. H. N.; Latorre, M. R. D. O.; J. Environ. Med. 1999, 1, 95.

46. Lipfert, F. W.; Environ. Health Persp. 1993, 101 (Suppl. 2), 229.

47. Reynolds, P.; Behren, J.; Gunier, R. B.; Goldberg, D. E.; Hertz, A.; Smith, D.; Cancer Causes Control 2002, 13, 665.

48. Sanhueza, P. A.; Reed, G. D.; Davis, W. T.; Miller, T. L.; Smith, S. M.; Clean Technol. Environ. Policy 2002, 4, 79.

49. Sunyer, J.; Spix, C.; Quénel, P.; Ponce-de-León, A.; Pönka, A.; Barumandzadeh, T.; Touloumi, G.; Bacharova, L.; Wojtyniak, B.; Vonk, J.; Bisanti, L.; Schwartz, J.; Katsouyanni, K.; Thorax 1997, 52, 760.

50. Junger, W. L.; Tese de Mestrado, Pontefícia Universidade Católica, Brasil, 2004.

51. Lambert, D.; Technometrics 1992, 34, 1. 
52. Cameron, A. C., Trivedi, P. K.; Regression Analysis of Count Data, Cambridge University Press: Cambridge, 1998.

53. Binder, H., Tutz, G.; Stat. Comput. 2008, 18, 87.

54. Sáez, M.; Sunyer, J.; Castellsagué, J., Murillo, C.; Mantó, J.; Int J. Epidemiol. 1995, 24, 576.

55. Dominici, F.; Sheppard, L.; Clyde, M.; Int. Stat. Rev. 2003, 71, 243.

56. Diggle, P. J.; Time series: a biostatistical introduction, Oxford University Press: Oxford, 1990.

57. Hastie, T., Tibshirani, R.; Generalized additive models, Chapman \& Hall: London, 1990.

58. Campbell, M. J.; Tobías, A.; Int. J. Epidemiol. 2000, 29, 271.

59. Dominici, F.; McDermott, A.; Zeger, S. L.; Samet, M.; Am. J. Epidemiol. 2002, 156, 193.

60. Segala, C.; Fauroux, B.; Just, J.; Pascual, L.; Grimfeld, A.; Neukirch, F.; Eur. Respir. J. 1998, 11, 677.

61. Atkinson, R. W.; Anderson, H. R.; Strachan, D. P.; Bland, J. M.; Bremner, S. A.; Ponce de León, A.; Eur. Resp. J. 1999, 13, 257.

62. Galán, I.; Tobías, A.; Banegas, J. R.; Aranguez, E.; Eur. Resp. J. 2003, 22,1 .

63. Tenias, J. M.; Ballester, F.; Rivera, M. L.; Occup. Environ. Med. 1998, 55,541 .

64. Brito, F. F.; Gimeno, P. M.; Martínez, C.; Tobias, A.; Suárez, L.; Guerra, F.; Borja, J. M.; Alonso, A. M.; Allergy 2007, 62, 1152.

65. Karr, C.; Lumley, T.; Schreuder, A.; Davis, R.; Larson, T.; Ritz, B.; Kaufman, J.; Am. J. Epidemiol. 2007, 165, 553.

66. Ritchie, I. M.; Lehnen, R. G.; Internet J. Pulm. Med. 2004, 4, N1.
67. Hajat, S.; Haines, A.; Goubet, S. A.; Atkinson, R. W.; Anderson, H. R.; Thorax 1999, 54, 597.

68. Joseph, P. M.; Environ. Int. 2007, 33, 1090.

69. Joseph, P. M.; Weiner, M. G.; Arch. Environ. Health 2002, 57, 137.

70. Tawnsend, C. L.; Maynard, R. L.; Occup. Environ. Med. 2002, 59, 708.

71. Spix, C.; Anderson, H. R.; Schwartz, J.; Vigotti, M. A.; Le Tertre, A.; Vonk, J. M.; Touloumi, G.; Balducci, F.; Piekarski, T.; Bacharoval, L.; Tobías, A.; Ponka, A.; Katsouyanni, K.; Arch. Environ. Health 1998, 53, 54.

72. Dab, W.; Medina, S.; Quenel, P.; J. Epidemiol. Commun. Health 1996, $50, \mathrm{~S} 42$.

73. Wong, T. W.; Lau, T. S.; Yu, T. S.; Neller, A.; Wong, S. L.; Tam, W.; Pang, S. W.; Occup. Environ. Med. 1999, 56, 679.

74. Luginaah, I. N.; Fung, K. Y. Gorey, K. M.; Webster, G.; Wills, C.; Environ. Health Persp. 2005, 113, 290.

75. Katsouyanni, K.; Schwartz, J.; Spix, C.; Touloumi, G.; Zmirou, D.; Zanobetti, A.; Wojtyniak, B.; Vonk, J. M.; Tobías, A.; Pönkä, A.; Medina, S.; Bachárová, L.; Anderson, H. R.; J. Epidemiol. Commun. Health 1996, 50, S12.

76. Braga, A. L. F.; Zanobetti, A., Schwartz, J.; Environ. Health Persp. 2002. 110, 859.

77. Patz, J. A.; Engelberg, D.; Last, J.; Annu. Rev. Public Health 2000, 21, 271.

78. Ren, C., Tong, S.; Environ. Health 2008, 7, 56.

79. Pandey, K. D.; Health impacts of outdoor air pollution. Urban air pollution - South Asia urban air quality, Management Briefing $N^{\circ} 14$, UNDP/ ESMAP, 2003. 


\section{AIR POLLUTION AND EMERGENCY ADMISSIONS FOR CARDIORESPIRATORY DISEASES IN LISBON (PORTUGAL)}

Célia A. Alves*

Centro de Estudos do Ambiente e do Mar, Departamento de Ambiente e Ordenamento, Universidade de Aveiro, 3810-193 Aveiro, Portugal Manuel G. Scotto

Departamento de Matemática, Universidade de Aveiro, 3810-193 Aveiro, Portugal

Maria do Carmo Freitas

Instituto Tecnológico e Nuclear, E.N. 10, 2686-953 Sacavém, Portugal
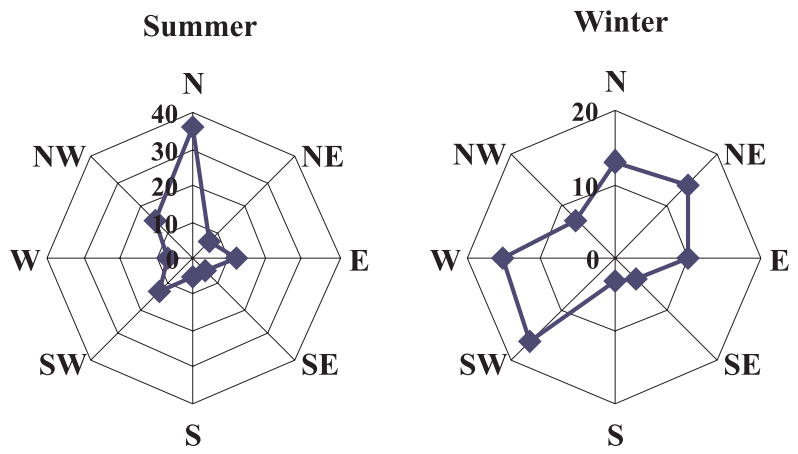

Figure 1S. Frequencies of wind directions in Lisbon. Values are given in percentage
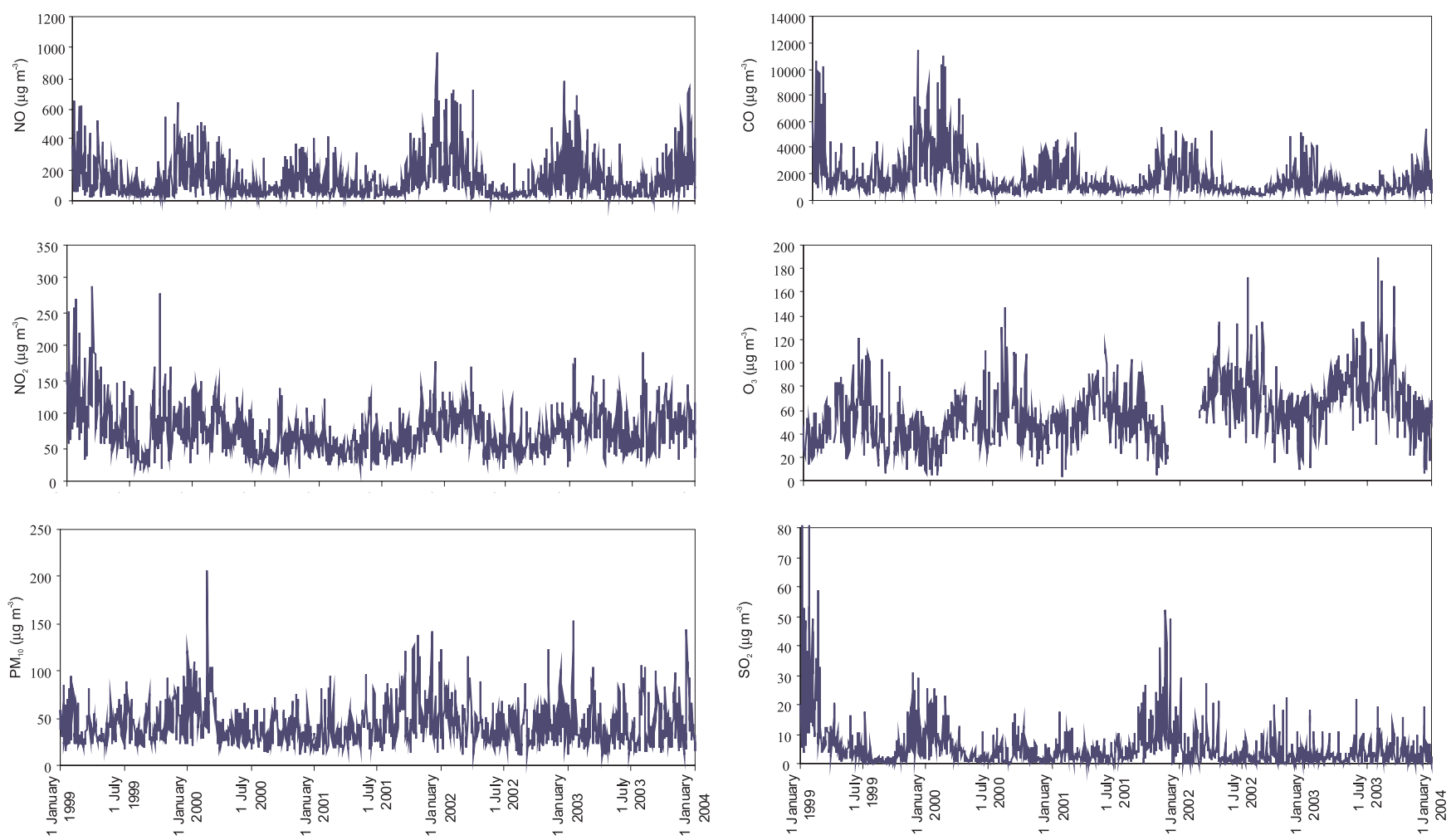

Figure 2S. Daily averages for the air pollution variable over the 1999-2004 period

*e-mail: celia.alves@ua.pt 

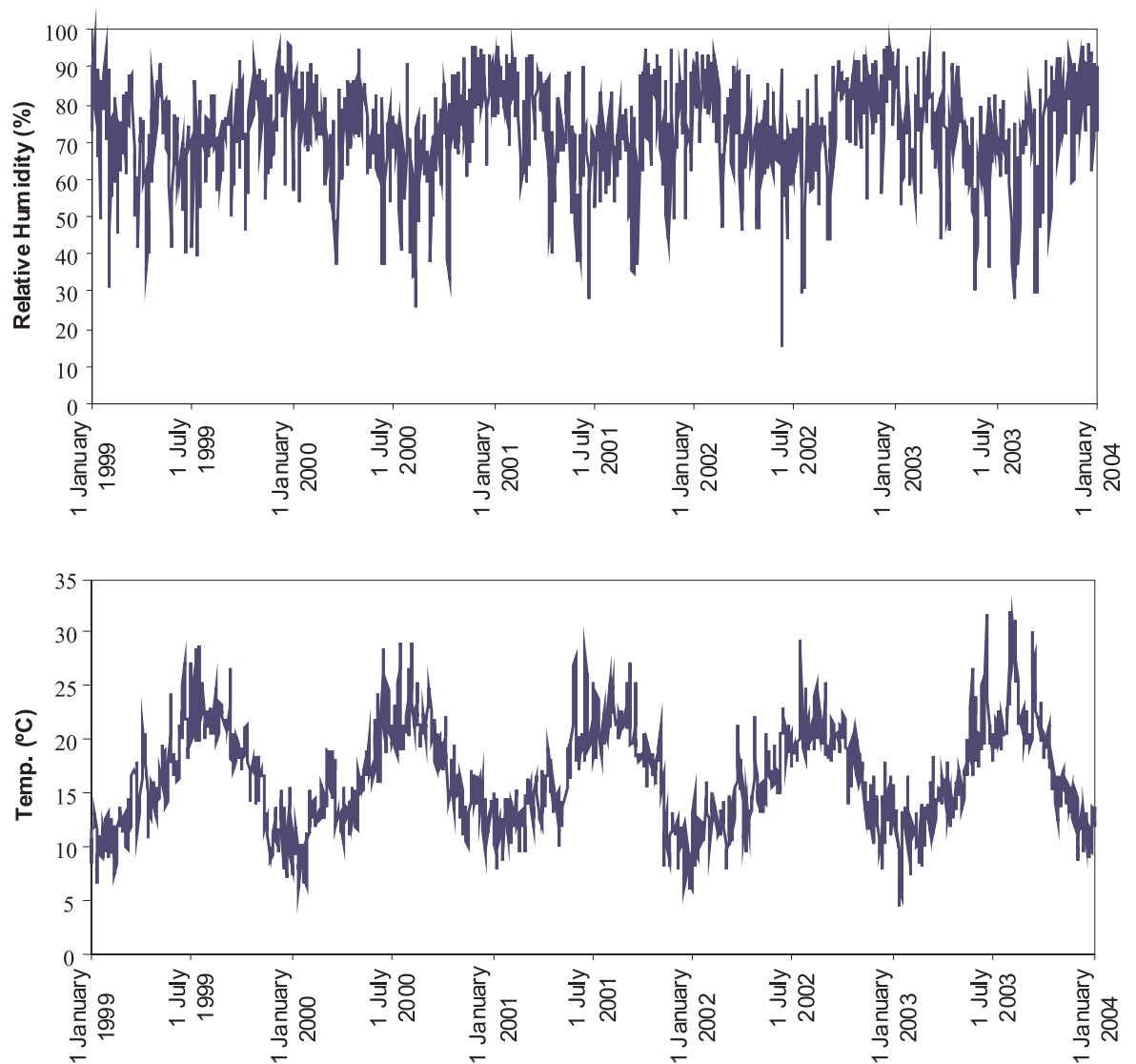

Figure 3S. Daily averages for the meteorological parameters over the 1999-2004 period 